\section{A comparison of the myocardial metabolic and haemodynamic changes produced by propofol-sufentanil and enflurane- sufentanil anaesthesia for patients having coronary artery bypass graft surgery}

Richard I. Hall MD FRCPC, *

J. Thomas Murphy MD FRCPC,* Emerson A. Moffitt MD FRCPC, ${ }^{*}$ Roderick Landymore MD FRCs, $\dagger$ P. Timothy Pollak MD PhD FRCPC, $\ddagger$ Laurie Poole BN RN*
The purpose of this study was to compare propofol-sufentanil with enflurane-sufentanil anaesthesia for patients undergoing elective coronary artery bypass graft (CABG) surgery with respect to changes in (1) haemodynamic variables; (2) myocardial blood flow and metabolism; (3) serum cortisol, triglyceride, lipoprotein concentrations and liver function; and (4) recovery characteristics. Forty-seven patients with preserved ventricular function (ejection fraction $>40 \%$, left ventricular end diastolic

Key words

ANAESTHETICS, VOLATILE: enflurane; ANAESTHETICS, INTRAVENOUS: sufentanil, propofol; HEART: metabolism;

SURGERY: cardiovascular.

From the Departments of Anaesthesia,* Surgery $\dagger$ and Medicine, $\ddagger$ Victoria General Hospital, Dalhousie University and the Maritime Heart Centre, Halifax, Nova Scotia, Canada.

Supported by a grant from ICI Pharmaceutica, Wilmington, Delaware. Drs. Hall and Pollak are PMAC/ MRC Health Research Foundation Scholars.

Presented in part at the Canadian Anaesthetists' Society Annual Meeting, Vancouver 1990, Quebec 1991, and the Sixty-fifth Congress of the International Anesthesia Research Society, San Antonio, Texas 1991.

Address correspondence to: Dr. R. Hall, Dept of Anaesthesia, Victoria General Hospital, Halifax, Nova Scotia, Canada B3H 2 Y9.

Accepted for publication 2nd July, 1991. pressure $\leq 16 \mathrm{mmHg}$ ) were studied. Patients in Group A $(n=24)$ received sufentanil $0.2 \mu \mathrm{g} \cdot \mathrm{kg}^{-1}$ and propofol $1-2 \mathrm{mg} \cdot \mathrm{kg}^{-1}$ for induction of anaesthesia which was maintained with a variable rate propofol (50-200 $\left.\mu \mathrm{g} \cdot \mathrm{kg}^{-1} \cdot \mathrm{min}^{-1}\right)$ infusion and supplemental sufentanil (maximum total $5 \mu \mathrm{g} \cdot \mathrm{kg}^{-1}$ ). Patients in Group $B(n=23)$ received sufentanil $5 \mu \mathrm{g} \cdot \mathrm{kg}^{-1}$ for induction of anaesthesia which was maintained with enflurane and supplemental sufentanil (maximum total $7 \mu \mathrm{g} \cdot \mathrm{kg}^{-1}$ ). Haemodynamic and myocardial metabolic profiles were determined at the awake-sedated, post-induction, post-intubation, first skin incision, post-sternotomy, and pre-cardiopulmonary bypass intervals. Induction of anaesthesia produced a larger reduction in systolic blood pressure in Group A (156 \pm 22 to $104 \pm 20$ $\mathrm{mmHg}$ vs $152 \pm 26$ to $124 \pm 24 \mathrm{mmHg} ; P<0.05)$. No statistical differences were detected at any other time or in any other variable including myocardial lactate production $(n=13$ events in each group), time to tracheal extubation and time to discharge from the ICU. We concluded that, apart from hypotension on induction of anaesthesia, propofol-sufentanil anaesthesia produced anaesthetic conditions equivalent to enflurane-sufentanil anaesthesia for CABG surgery.

Afin de comparer l'anesthésie au propofol-sufentanil avec celle d l'enflurane-sufentanil pour pontage aorto-coronarien électif concernant les variations dans I) les données hémodynamiques; 2) le flot sanguin myocardique et métabolisme; 3) la concentration sérique du cortisol, les triglycérides, les lipoprotéines et la fonction hépatique, 4) les caractéristiques de réveil. Quarantesept patients avec une fonction ventriculaire préservée (fraction 
d'éjection $>40 \%$, pression diastolique de ventricule gauche à $16 \mathrm{mmHg}$ ) ont été étudiés. Les patients du groupe $\mathrm{A}(\mathrm{n}=24)$ ont reçu du sufentanil $0.2 \mu \mathrm{g} \cdot \mathrm{kg}^{-1}$ et du propófol l-2 $\mathrm{mg} \cdot \mathrm{kg}^{-1}$ pour l'induction de l'anesthésie qui fut maintenue avec des taux variables de perfusion de propofol $\left(50-200 \mu \mathrm{g} \cdot \mathrm{kg}^{-1} \cdot \mathrm{min}^{-1}\right)$ et un supplément de sufentanil (maximum total $5 \mu \mathrm{g} \cdot \mathrm{kg}^{-1}$ ). Les patients du groupe $B(n=23)$ ont reçu du sufentanil $5 \mu \mathrm{g} \cdot \mathrm{kg}^{-1}$ pour l'induction de l'anesthésie qui fut maintenu avec l'enflurane et des doses supplémentaires de sufentanil (dose totale maximale $7 \mu \mathrm{g} \cdot \mathrm{kg}^{-1}$ ). Les profils myocardique et hémodyna. mique ont été déterminé alors que le patient était réveillé sédationné, après l'induction, à l'incision cutanée, après sternotomie, et avant la CEC. L'induction de l'anesthésie a produit une plus grande diminution de la pression artérielle systolique dans le groupe $A(156 \pm 22$ a $104 \pm 20 \mathrm{mmHg}$ vs 152 \pm 26 à $124 \pm 24 \mathrm{mmHg} ; P<0,05)$. Aucune différence statistique significative ne fut détectée en aucun temps ni en aucune des autres variables incluant la production de lactate par le myocarde ( $n=13$ evénéments dans chaque groupe), el le temps de l'extubation jusqu'au congé des soins intensifs. On conclut qu'à part l'hypotension lors de l'induction de l'anesthésie, le propofol-sufentanil était similaire d̀ l'enfluranesufentanil pour la chirurgie de pontage aorto-coronarien électif.

Patients scheduled for elective cardiac surgery in Canada may expect to wait 3-6 months before surgery is undertaken. Because of this backlog, consideration should be given to anaesthetic techniques which allow early tracheal extubation and permit more efficient use of cardiovascular ICU beds. Whatever anaesthetic technique is employed, it must provide: (1) intraoperative cardiovascular stability; (2) minimal myocardial depression; and (3) rapid offset of anaesthetic action without postoperative haemodynamic instability. The current anaesthetic techniques employed during cardiac surgery do not satisfy these criteria. High doses of opioids alone are not sufficient to maintain haemodynamic stability ${ }^{1,2}$ and may be associated with intraoperative recall of surgical events. ${ }^{3,4}$ Their use mandates admission to the intensive care unit for assisted ventilation (usually overnight) and occasionally prolonged ventilatory assistance is required entailing an increased risk for the development of nosocomial pneumonia. ${ }^{5,6}$ Addition of other agents to prevent awareness and improve blood pressure control may produce increased myocardial depression. ${ }^{7}$ On the other hand, primary use of volatile agents is associated with more haemodynamic variability and myocardial depression than opioid-based techniques. ${ }^{8}$

Propofol, a substituted phenol, is a short-acting anaesthetic agent with a favourable haemodynamic and recovery profile. ${ }^{9}$ These features led us to consider its use in anaesthesia for cardiac surgery. Limited data exist concerning its use for anaesthesia for patients undergoing heart surgery.${ }^{9-16}$ Hypotension, primarily on induction of anaesthesia, has been described ${ }^{9}$ but the mechanism for this is uncertain. ${ }^{17-20}$ When used as the primary anaesthetic agent during cardiac surgery its effects on myocardial metabolism and oxygenation are unknown. In short surgical procedures it does not inhibit the stress response to surgery, ${ }^{21}$ but its effects on stress response during longer or more stressful procedures have not been documented. The effect of its formulation in an egglecithin emulsion on lipid metabolism during prolonged infusions has not been reported. Also, its lack of analgesic activity suggests that some combination of opioid with propofol would be required during cardiac surgery but this has yet to be investigated.

Before undertaking studies designed to examine the potential of early tracheal extubation to reduce cardiac surgical waiting lists, the safety and efficacy of the proposed anaesthetic technique for use during cardiac surgery must first be demonstrated. To investigate some of these issues, we designed a randomised, prospective study to compare the use of propofol-sufentanil with enflurane-sufentanil anaesthesia for patients with preserved ventricular function undergoing elective coronary artery bypass graft surgery (CABG). The two techniques were compared with respect to (1) changes in haemodynamic variables; (2) changes in myocardial blood flow and metabolism; (3) changes in cortisol, triglyceride, and high density lipoprotein concentrations and liver function; and (4) recovery characteristics.

\section{Methods}

\section{Patient selection criteria}

Patients aged 40-75 yr, and scheduled for elective CABG surgery with left ventricular end diastolic pressure $\leq 16$ $\mathrm{mmHg}$, and an ejection fraction of $>40 \%$, were included in the study. Patients with severe systemic, non-cardiac disease (e.g., unstable diabetes) were excluded.

\section{Medications}

Following protocol approval by the United States Food and Drug Administration, Canadian Health Protection Branch, and the institution, informed consent was obtained from each patient. On the evening before surgery chloral hydrate $1 \mathrm{~g}$ was administered $p o$. Patients continued to receive their routine cardiac medications until the time of surgery. Approximately $1.5 \mathrm{hr}$ before surgery, diazepam $0.1-0.2 \mathrm{mg} \cdot \mathrm{kg}^{-1}$ was administered po followed by morphine $0.1-0.2 \mathrm{mg} \cdot \mathrm{kg}^{-1}$ and promethazine $0.25-0.5 \mathrm{mg} \cdot \mathrm{kg}^{-1} \mathrm{im}$ one hour before surgery. 


\section{Laboratory examinations}

All patients had an ECG and CXR within the previous three months. Blood was analysed for complete blood count, prothrombin time, partial thromboplastin time; serum electrolytes including sodium, potassium, chloride, bicarbonate, serum inorganic phosphate; liver enzymes including serum glutamic oxaloacetic transaminase (SGOT or AST), serum glutamic pyruvate transaminase (SGPT or ALT), lactate dehydrogenase (LDH) (utilizing a Hitachi 717 System $^{22}$ ); lipid profile including high density lipoproteins (HDL), triglycerides, cholesterol (CHOL) utilizing a colorimetric test (Kodak Ektachem ${ }^{\boxplus}$ ); cortisol utilizing a radioimmunoassay (Gamma Coat $\left.{ }^{125} \mathrm{I}\right]$ Cortisol); glucose, blood urea nitrogen, and creatinine. These examinations were performed again on the morning after surgery.

\section{Monitors}

Supplemental oxygen was administered by facemask. A three lead ECG was placed in the $V_{5}$ position. A digital pulse oximeter and an end-tidal carbon dioxide monitor were used. Under local anaesthesia, iv cannulae and a radial arterial cannula were inserted. A pulmonary artery catheter was positioned in the pulmonary artery and a coronary sinus catheter was positioned in the mid-distal one-third of the coronary sinus.

\section{Randomization procedure}

When the monitors and vascular catheters were secured, the patients were randomly allocated to one of the study groups.

\section{Anaesthetic technique}

Patients in Group A (propofol-sufentanil) received sufentanil $0.2 \mu \mathrm{g} \cdot \mathrm{kg}^{-1}$ iv over one minute followed by propofol $1-2 \mathrm{mg} \cdot \mathrm{kg}^{-1} i v$ over 1-3 min. Upon loss of eyelid reflex, an iv maintenance infusion of propofol 50 $\mu \mathrm{g} \cdot \mathrm{kg}^{-1} \cdot \mathrm{min}^{-1}$ was initiated using a calibrated Baxter AS20GH pump and the infusion rate was adjusted by 50 $\mu \mathrm{g} \cdot \mathrm{kg}^{-1}$ increments (maximum $200 \mu \mathrm{g} \cdot \mathrm{kg}^{-1} \cdot \mathrm{min}^{-1}$ ) or decrements (minimum $50 \mu \mathrm{g} \cdot \mathrm{kg}^{-1} \cdot \mathrm{min}^{-1}$ ) throughout the surgical procedure. In addition, sufentanil $1 \mu \mathrm{g} \cdot \mathrm{kg}^{-1}$ was administered at five-minute intervals when surgical stimulation produced adverse haemodynamic changes (defined as an increase of $20 \%$ above the mean ward systemic pressure or an increase in heart rate (HR) greater than $10 \%$ of the mean ward heart rate or an absolute limit of $90 \mathrm{bpm}$ ). Additional vasodilators could be used for control of blood pressure and beta adrenergic blockers to control heart rate. In the event of hypotension, defined as a mean systemic arterial pressure less than $50 \mathrm{mmHg}$ or $20 \%$ below the mean ward pressure for one minute, vasopressors (neosynephrine or ephedrine) were adminis- tered and the propofol infusion rate was decreased by 50 $\mu \mathrm{g} \cdot \mathrm{kg}^{-1} \cdot \mathrm{min}^{-1}$ steps at 2-5 min intervals to a minimum of $50 \mu \mathrm{g} \cdot \mathrm{kg}^{-1} \cdot \mathrm{min}^{-1}$. During cardiopulmonary bypass, a minimum infusion rate of $50 \mu \mathrm{g} \cdot \mathrm{kg}^{-1} \cdot \mathrm{min}^{-1}$ was maintained. The propofol infusion was discontinued at the time of skin closure.

Patients in Group B (enflurane-sufentanil) received sufentanil $5 \mu \mathrm{g} \cdot \mathrm{kg}^{-1}$ iv over 1-3 min. Enflurane, $0.25-3 \%$ inspired, was added when increases in heart rate $>10 \%$ of the mean ward heart rate or $90 \mathrm{bpm}$ absolute or increases $>20 \%$ of the mean ward systemic blood pressure occurred and the concentration was adjusted accordingly. End-tidal enflurane concentration was measured utilizing a Datex Anaesthesia Agent Monitor. Subsequent adverse haemodynamic events were treated with sufentanil $1 \mu \mathrm{g} \cdot \mathrm{kg}^{-1}$ (to a total dose of $7 \mu \mathrm{g} \cdot \mathrm{kg}^{-1}$ ) and increasing the concentration of enflurane administered (maximum 3\% inspired). In the event of hypotension, vasopressors such as neosynephrine or ephedrine were administered, the enflurane concentration was reduced by decrements of $0.5 \%$ at $2-5 \mathrm{~min}$ intervals to a minimum of $0.25 \%$. Enflurane was administered into the oxygenator during cardiopulmonary bypass at the discretion of the anaesthetist.

In both groups pancuronium was used to facilitate tracheal intubation and to provide neuromuscular relaxation. To prevent awareness, diazepam $0.15 \mathrm{mg} \cdot \mathrm{kg}^{-1}$ iv was administered to patients in both groups prior to initiation of cardiopulmonary bypass and $0.05 \mathrm{mg} \cdot \mathrm{kg}^{-1}$ was administered at skin closure to slow the emergence from anaesthesia during transport to the intensive care unit.

\section{Conduct of cardiopulmonary bypass (CPB)}

A crystalloid priming solution, bubble $(n=43)$ and membrane ( $n=4)$ oxygenators, an in-line arterial filter, and flow rates of $2.5 \mathrm{~L} \cdot \mathrm{min}^{-1} \cdot \mathrm{m}^{-2}$ with hypothermia to $25-28^{\circ}(n=36)$ or normothermia $(n=11)$ were employed. Mean systemic pressures of $50-70 \mathrm{mmHg}$ were maintained. Blood gases were maintained using a temperature uncorrected technique. Coronary artery bypass surgery was performed and cardiopulmonary bypass terminated. At this point, vasodilator and inotropic agents were administered if necessary.

\section{Haemodynamic and metabolic measurements}

A 4-channel strip chart (Siemens Model SIREDOC) continuously recorded the systemic arterial, pulmonary arterial, and central venous pressure until the onset of cardiopulmonary bypass. The mean systemic pressure was calculated at ten-minute intervals during cardiopulmonary bypass. Following termination of cardiopulmonary bypass, recording of systemic, central venous, and 
pulmonary arterial pressures and heart rate was resumed.

The following haemodynamic and metabolic measurements were made at the control (awake, sedated), post-induction, post-intubation, first skin incision, poststernotomy, and prior to cardiopulmonary bypass intervals: cardiac output (Siemens Model VG:404-1 thermodilution device with two values replicated within $10 \%$ of each other); pulmonary artery occlusion pressure; coronary sinus blood flow (thermodilution technique - Webster Laboratories Inc.); systemic arterial and coronary sinus blood gases; and systemic arterial and coronary sinus blood lactate levels (utilizing a REA ${ }^{\otimes}$ Lactic Acid Kit Abbott Laboratories Inc.). Derived indices included the cardiac index, systemic and pulmonary vascular resistance index, myocardial lactate extraction, and myocardial oxygen consumption utilizing standard formulae.

\section{Electrocardiographic measurements}

Lead $V_{5}$ of the electrocardiogram was continuously recorded at $1 \mathrm{~mm} \cdot \mathrm{sec}^{-1}$. At each study point, the paper speed was increased to $25 \mathrm{~mm} \cdot \mathrm{sec}^{-1}$ to allow for analysis of ST segment elevation or depression measured $40 \mathrm{msec}$ beyond the $\mathrm{J}$ point deflection. The baseline was taken as the position recorded during the awake, sedated study period.

\section{Intensive care phase and outcome measurements}

The nursing staff were blinded regarding treatment group. Nursing notes were consulted to determine times to awakening and movement of all limbs in response to direct commands, tracheal extubation, amount and type of sedation, inotropic and vasodilator agents employed, and presence of nausea and vomiting. Following tracheal extubation and $24 \mathrm{hr}$ after discharge from the Unit, patients were questioned about their memory of events in the perioperative period and their anaesthetic experience. Perioperative myocardial infarction was diagnosed when new ECG changes occurred with a positive CKMB fraction $>4 \%$ of the total measured creatinine phosphokinase level and a ratio of lactate dehydrogenase : lactate $_{1}$

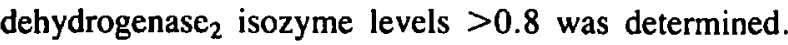
Major adverse neurological outcome was considered to have occurred when a gross focal neurological deficit not present preoperatively was detected and persisted for $>24$ hr in the postoperative period.

\section{Statistical analysis}

Between group differences were determined by a repeated measures analysis of variance technique with time and group as cofactors, Chi-square analysis, and either paired or unpaired $t$ tests with Bonferroni correction as appropriate. A power analysis determined that, with myocardial lactate extraction as the variable of interest and $\alpha=0.05$,
TABLE I Demographic data (all results mean \pm SD)

\begin{tabular}{|c|c|c|}
\hline Variable & Group A & Group B \\
\hline$n$ & 24 & 23 \\
\hline Age (yr) & $58 \pm 9.8$ & $57 \pm 8.2$ \\
\hline Weight (kg) & $77.6 \pm 14.2$ & $82.0 \pm 11.3$ \\
\hline $\operatorname{BSA}\left(\mathrm{m}^{2}\right)$ & $1.9 \pm 0.2$ & $2.0 \pm 0.2$ \\
\hline $\operatorname{Sex}(m / f)$ & $18 / 6$ & $23 / 0^{*}$ \\
\hline ASA class II/III//V & $0 / 21 / 3$ & $1 / 22 / 0$ \\
\hline \multicolumn{3}{|l|}{ Medical history: } \\
\hline Hypertension & 7 & 5 \\
\hline Smoker & 2 & 1 \\
\hline Diabetes (Type II) & 4 & 2 \\
\hline Previous MI & 10 & 8 \\
\hline Hypercholesterolaemia & 5 & 5 \\
\hline \multicolumn{3}{|l|}{ Cardiac function: } \\
\hline Ejection fraction (\%) & $62.5 \pm 16.4$ & $64.5 \pm 16.6$ \\
\hline \multicolumn{3}{|l|}{ Left ventricular end } \\
\hline $\begin{array}{l}\text { diastolic pressure } \\
(\mathrm{mmHg})\end{array}$ & $9.9 \pm 3.5$ & $11.7 \pm 2.9$ \\
\hline 1 Vessel discase & 1 & 2 \\
\hline 2 Vessel discase & 13 & 11 \\
\hline 3 Vessel disease & 8 & 7 \\
\hline Left main disease & 2 & 3 \\
\hline \multicolumn{3}{|l|}{ Medication } \\
\hline $\begin{array}{l}\text { Beta adrencrgic } \\
\text { blocking agent }\end{array}$ & Beta adrencrgic & 19 \\
\hline \multicolumn{3}{|l|}{ Calcium entry } \\
\hline blocking agent & 20 & 19 \\
\hline Nitrates & 18 & 15 \\
\hline
\end{tabular}

${ }^{*} P<0.05$ vs Group A.

there was a $78 \%$ chance of detecting a $20 \%$ difference between the two groups with 20 patients studied in each group.

\section{Results}

Fifty patients were approached to participate in the study: two declined and one patient was withdrawn by the investigators.

The demographic data for the 47 patients studied are given in Table I (all results mean \pm SD). Despite randomization, all six women were enrolled in Group A (propofol-sufentanil) which was different from Group B (enflurane-sufentanil) $(P<0.05)$. The groups were evenly matched for all other variables, including medications (Table I). In Group A, the average induction dose of propofol was $1.1 \pm 0.2 \mathrm{mg} \cdot \mathrm{kg}^{-1}$ and the total maintenance dose was $25.4 \pm 7.9 \mathrm{mg} \cdot \mathrm{kg}^{-1}$.

The two groups did not differ with respect to surgical course, specifically, the duration of anaesthesia (Group A, $273 \pm 88$ vs Group B, $272 \pm 62 \mathrm{~min}$ ); CPB (Group A, $94 \pm 51$ vs Group B, $93 \pm 40 \mathrm{~min}$ ), and aortic cross-clamp time (Group A, $48 \pm 20$ vs Group B, $52 \pm 22$ $\mathrm{min}$ ). The number of grafts (Group A, $2.9 \pm 0.9$ vs Group $B, 3.0 \pm 0.7)$ received and number of patients receiving 


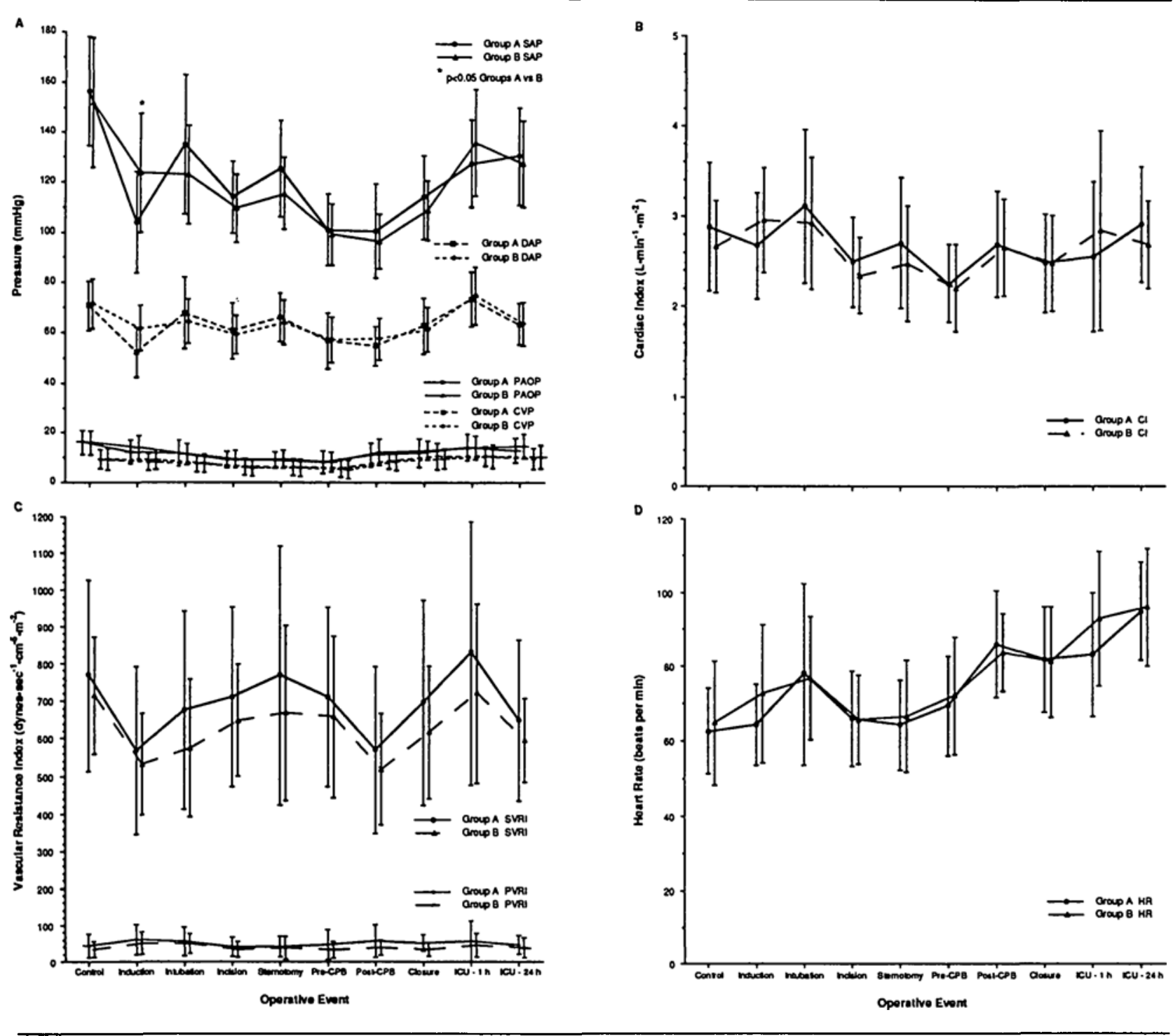

FIGURE I Changes in systolic and diastolic arterial pressures, pulmonary artery occlusion, and central venous pressures (Panel A), cardiac index (Panel B), systemic vascular resistance index, and pulmonary vascular resistance index (Panel $C-$ values where PVRI $=0$ or a negative number excluded), and heart rate (Panel D) at the indicated intraoperative event. Group A ( $n=24)$ received propofol-sufentanil anaesthesia and Group B $(n=23)$ received enflurane-sufentanil anaesthesia. All results Mean \pm SD.

internal mammary artery (IMA) grafts was similar (Group A, $n=20$ vs Group B, $n=22)$, as was the number of patients having normothermic $\mathrm{CPB}$ (Group $\mathrm{A}, n=5$ vs Group $\mathrm{B}, n=6$ ) and use of a membrane oxygenator (Group A, $n=3$ vs Group B, $n=1$ ).

Intraoperative requirement for vasodilators (Group A, $n=22$ vs Group $\mathrm{B}, n=18$ events) or vasopressors (Group A, $n=30$ vs Group B, $n=23$ events) (NB: some patients required more than one agent) was not different. No difference was detected in the number of patients requiring vasoactive agents post-induction (Group $\mathrm{A}, n$ $=4$ vs Group $B, n=0$ ), prior to initiation of cardiopulmonary bypass (Group A, $n=1$ vs Group B, $n=6$ ), immediately after initiation of cardiopulmonary bypass (Group A, $n=14$ vs Group B, $n=8$ ), or to facilitate separation from cardiopulmonary bypass (Group A, $n=6$ vs Group B, $n=5$ ).

Systolic and mean blood pressures decreased to a greater extent following induction of anaesthesia in the propofol-treated group $(P<0.05)$ (Figure 1). Following intubation, blood pressure exceeded the awake value in six patients in Group A and five in Group B $(P=N S)$ and this was accompanied by an increase in heart rate $>20 \%$ above the control value in ten patients in Group $A$ and nine in Group B $(P=N S)$. Following induction of anaesthesia, no differences were detected between the two groups 


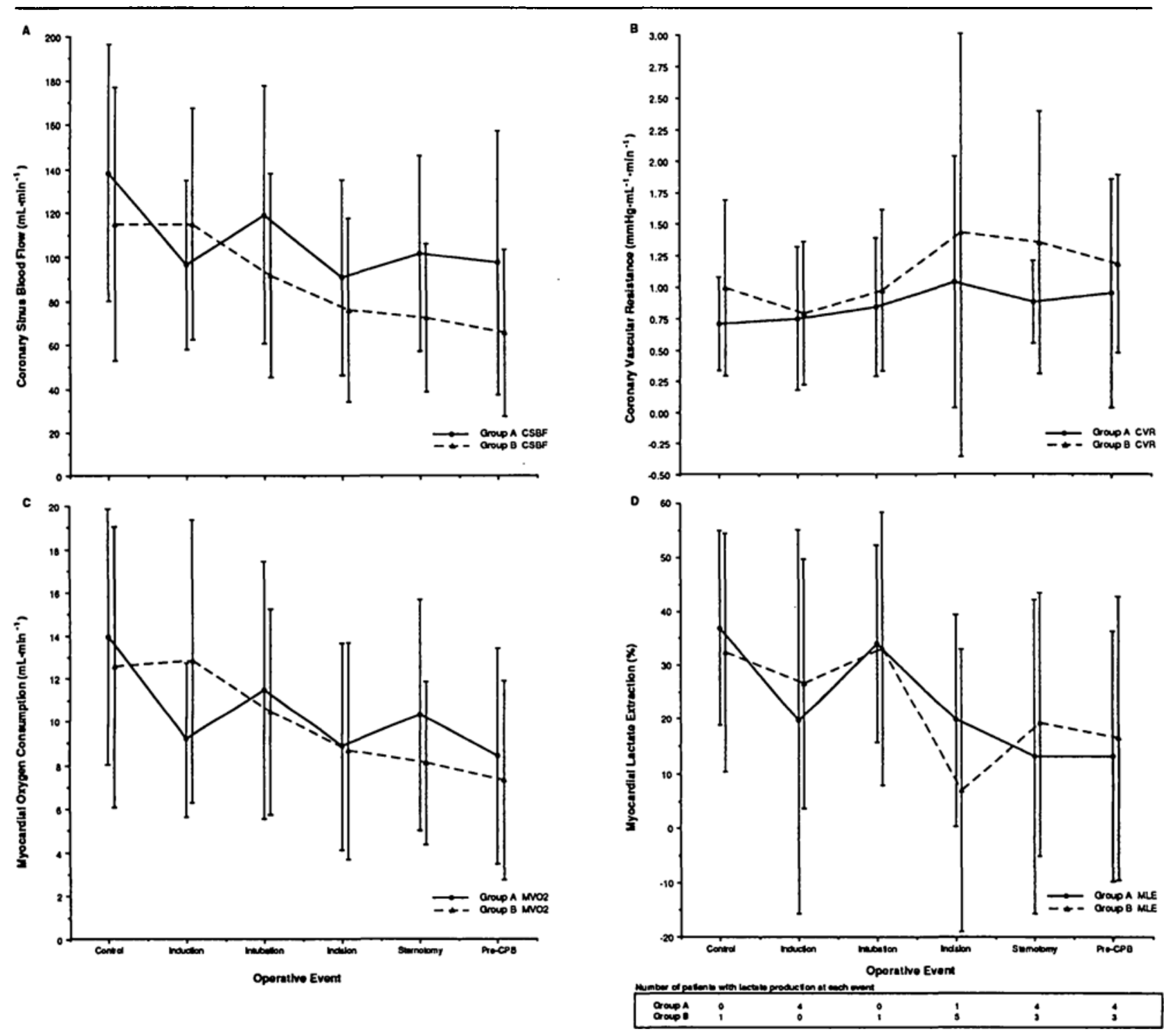

FIGURE 2 Changes in coronary sinus blood flow (Panel A), coronary vascular resistance (Panel B), myocardial oxygen consumption (Panel C), and myocardial lactate extraction (Panel D) at the indicated intraoperative event. The number of patients producing myocardial lactate at cach measurement point is indicated in Panel D. Group A $(n=20)$ received propofol-sufentanil anaesthesia and Group B $(n=20)$ received enflurane-sufentanil anaesthesia.

for any haemodynamic variable at any time (Table $\mathrm{II}$, Figure 1).

Coronary sinus catheter malfunction or displacement prevented collection of a complete data set in seven patients (Group A, $n=4$ and Group B, $n=3$ ) and data are presented for 40 patients. There were no betweengroup differences in ST segment changes, myocardial oxygen consumption, lactate extraction, coronary sinus blood flow or coronary vascular resistance (Table II; Figure 2).

No differences were detected between the two groups in liver enzymes, plasma triglycerides, and cortisol levels, although differences existed in some variables prevs postoperatively, e.g., (1) cortisol levels: preoperatively, Group A $(n=10) 411 \pm 197$ vs Group B $(n=9)$ $491 \pm 191 \mathrm{mmol} \cdot \mathrm{L}^{-1}$; postoperatively, Group A $630 \pm$ 175 vs Group B $669 \pm 374 \mathrm{mmol} \cdot \mathrm{L}^{-1}(P=\mathrm{NS})$; (2) triglyceride levels: preoperatively, Group A $(n=24) 2.7$ \pm 1.3 vs Group B $(n=23) 3.1 \pm 2.4 \mathrm{mmol} \cdot \mathrm{L}^{-1}(P=\mathrm{NS})$; postoperatively, Group A $1.8 \pm 0.9(P<0.05$ vs preoperative value) vs Group B $1.7 \pm 1.3 \mathrm{mmol} \mathbf{L}^{-1}(P<0.05$ vs preoperative value; $P=$ NS vs Group $A$ ). 
TABLE II Changes in haemodynamic and myocardial metabolic variables

\begin{tabular}{|c|c|c|c|c|c|c|}
\hline Variable & $\begin{array}{l}\text { Awake } \\
\text { sedated }\end{array}$ & $\begin{array}{l}\text { Post- } \\
\text { induction }\end{array}$ & $\begin{array}{l}\text { Post- } \\
\text { intubation }\end{array}$ & $\begin{array}{l}\text { First } \\
\text { incision }\end{array}$ & $\begin{array}{l}\text { Post- } \\
\text { sternotomy }\end{array}$ & $\begin{array}{l}\text { Pre- } \\
\text { bypass }\end{array}$ \\
\hline \multicolumn{7}{|c|}{ St segment changes (mm) } \\
\hline Group A & $2.0 \pm 1.7$ & $1.9 \pm 1.7$ & $1.8 \pm 1.6$ & $1.8 \pm 1.7$ & $2.0 \pm 1.7$ & $1.6 \pm 1.7$ \\
\hline Group B & $1.9 \pm 1.8$ & $2.1 \pm 1.3$ & $2.1 \pm 1.3$ & $2.3 \pm 1.4$ & $2.4 \pm 1.5$ & $2.3 \pm 1.4$ \\
\hline \multicolumn{7}{|c|}{ Stroke volume index $\left(\mathrm{ml} \cdot\right.$ beat $\left.^{-1} \cdot \mathrm{m}^{-2}\right)$} \\
\hline Group A & $46 \pm 8$ & $42 \pm 8$ & $42 \pm 12$ & $38 \pm 8$ & $43 \pm 12$ & $33 \pm 9$ \\
\hline Group B & $42 \pm 9$ & $42 \pm 10$ & $40 \pm 11$ & $37 \pm 8$ & $39 \pm 13$ & $32 \pm 8$ \\
\hline \multicolumn{7}{|c|}{ Left ventricular stroke work index $\left(\mathrm{gm} \cdot \mathrm{m} \cdot \mathrm{m}^{-2}\right)$} \\
\hline Group A & $52 \pm 11$ & $33 \pm 10$ & $44 \pm 14$ & $36 \pm 10$ & $45 \pm 14$ & $28 \pm 7$ \\
\hline Group B & $47 \pm 12$ & $39 \pm 12$ & $39 \pm 14$ & $33 \pm 10$ & $38 \pm 14$ & $27 \pm 8$ \\
\hline \multicolumn{7}{|c|}{ Myocardial oxygen extraction (mmol L-1) } \\
\hline Group $A(A)$ & $1.4 \pm 0.5$ & $1.4 \pm 0.5$ & $1.5 \pm 0.5$ & $1.5=0.6$ & $1.6 \pm 0.6$ & $1.7 \pm 0.6$ \\
\hline (V) & $0.9 \pm 0.3$ & $1.1 \pm 0.5$ & $1.0 \pm 0.4$ & $1.2 \pm 0.5$ & $1.3 \pm 0.5$ & $1.5 \pm 0.6$ \\
\hline Group $B(A)$ & $2 . ! \pm 3.6$ & $1.3 \pm 0.7$ & $1.3 \pm 0.7$ & $1.3 \pm 0.7$ & $1.4 \pm 0.7$ & $1.7 \pm 0.6$ \\
\hline (V) & $1.0 \pm 0.5$ & $0.9 \pm 0.6$ & $0.9 \pm 0.6$ & $1.2 \pm 0.6$ & $1.2 \pm 0.6$ & $1.4 \pm 0.7$ \\
\hline \multicolumn{7}{|c|}{$\mathrm{CSO}_{2}$ content (ml dl $\left.{ }^{-1}\right)$} \\
\hline Group A & $7.8 \pm 2.0$ & $8.3 \pm 1.9$ & $7.8 \pm 1.6$ & $7.1 \pm 1.5$ & $6.6 \pm 1.4$ & $6.8 \pm 1.4$ \\
\hline Group B & $8.1 \pm 2.3$ & $7.5 \pm 1.8$ & $7.2 \pm 1.4$ & $6.8 \pm 0.9$ & $6.7 \pm 0.9$ & $7.3 \pm 1.2$ \\
\hline \multicolumn{7}{|c|}{ Arterial hemoglobin concentration $\left(\mathrm{g} \mathrm{L}^{-1}\right)$} \\
\hline Group A & $12.8 \pm 1.6$ & $12.6 \pm 1.7$ & $12.1 \pm 1.6$ & $11.9 \pm 1.5$ & $11.7 \pm 1.5$ & $11.0 \pm 1.8$ \\
\hline Group B & $13.8 \pm 1.2$ & $13.2 \pm 1.2$ & $13.2 \pm 1.3$ & $12.6 \pm 1.2$ & $12.2 \pm 1.6$ & $11.8 \pm 1.5$ \\
\hline
\end{tabular}

$* P<0.05$ vs Group B.

Differences in the recovery evaluations between the groups were not detected. Tracheal extubation occurred at $26.9 \pm 15.7 \mathrm{hr}$ in Group A vs $29.5 \pm 27.0 \mathrm{hr}$ in Group B (elapsed time from induction of anaesthesia) and discharge from the ICU at $50.0 \pm 26.9 \mathrm{hr}$ (Group A) vs 59.8 $\pm 48.5 \mathrm{hr}$ (Group B).

There were no deaths. One patient in each group developed a neurological deficit postoperatively and one patient in each group developed perioperative myocardial infarction. No patient reported awareness of any intraoperative event following induction of anaesthesia.

\section{Discussion}

This randomized study compared the haemodynamic and myocardial metabolic effects of propofol-sufentanil with those of enflurane-sufentanil anaesthesia during coronary artery surgery in patients with preserved ventricular function. Propofol-sufentanil produced reductions in systolic $(-33 \% ; P<0.05$ vs enflurane-sufentanil (Group B)), and diastolic ( $-27 \%$ vs $-14 \%$ in Group B) blood pressures on induction of anaesthesia. Both forms of anaesthesia produced similar reductions in vascular resistance index ( $-25 \%$ vs $-25 \%$ in Group B), left ventricular stroke work index $(-37 \%$ vs $-17 \%$ in Group B) and pulmonary artery occlusion pressure $(-25 \%$ vs $-13 \%$ in
Group B) with minimal changes in heart rate $(+3 \%$ vs $12 \%$ in Group B), central venous pressure $(-10 \%$ vs $0 \%$ in Group B), stroke volume index ( $-9 \%$ vs $0 \%$ in Group B), or cardiac index ( $-7 \%$ vs $+11 \%$ in Group B). Apart from hypotension on induction of anaesthesia, propofoltreated patients had no increase in adverse effects including myocardial ischaemia, or changes in haemodynamic profile or myocardial metabolic indices. Propofol-treated patients did not awaken earlier postoperatively, although trends towards earlier extubation and discharge from the intensive care unit emerged. Propofol-treated patients received a lower total dose of sufentanil, but the dose received $\left(2.2 \mu \mathrm{g} \cdot \mathrm{kg}^{-1}\right)$ was still substantial and both groups received diazepam as part of the anaesthetic. Use of sedation and analgesia in the ICU was not restricted. The role which these factors may have played in our recovery observations is unknown but potentially large. Previous data suggests that changes in propofol pharmacokinetic behaviour following cardiopulmonary bypass are an unlikely explanation. ${ }^{16}$

Administration of propofol was not associated with increased requirements for inotropic support for separation from cardiopulmonary bypass or an increased incidence of low cardiac output syndrome postoperatively.

Changes in myocardial blood flow and coronary 
vascular resistance paralleled changes in myocardial oxygen consumption and therefore neither anaesthetic technique uncoupled myocardial autoregulation.

Previous studies in cardiac patients have shown that hypotension on induction of anaesthesia with propofol is common ${ }^{10-12}$ and is associated with a reduction in cardiac index and stroke volume index. " Stephan et al. " also noted myocardial lactate production in two patients and a reduction in myocardial lactate extraction in the group as a whole, prior to cardiopulmonary bypass. For maintenance of anaesthesia, propofol produced a stable anaesthetic course following fentanyl induction. ${ }^{13-14}$

Cardiac surgical patients with preserved ventricular function, receiving propofol for induction and maintenance anaesthesia, were studied by Vermeyen et al. ${ }^{15}$ They noted reductions in systolic $(-28 \%)$, and diastolic $(-23 \%)$ blood pressure, systemic vascular resistance $(-25 \%)$, and left ventricular stroke work index $(-32 \%)$ on induction of anaesthesia. There was no increase in cardiac index or heart rate, and no changes in cardiac filling pressures.

Whether propofol produces primarily myocardial depression or vasodilatation has been the subject of some debate. ${ }^{17-20}$ The haemodynamic changes observed may simply reflect the introduction of the anaesthetic state and concomitant withdrawal of sympathetic stimulation. Indeed, myocardial oxygen consumption paralleled the haemodynamic changes suggesting that myocardial demand also decreased at this time. Cardiac index then increased with noxious stimulation at the time of endotracheal intubation largely due to increases in heart rate with very little change in stroke volume index. Parallel changes in myocardial oxygen consumption occurred indicating that the ability of the heart to respond to increased demands remained intact and the degree of myocardial depression was minimal. These results imply that, until further data are available, propofol should be used with care in patients with impaired myocardial function as they may be unable to mount a response to the same degree as patients with preserved myocardial function. Propofol produced no increased requirements for inotropic support during separation from cardiopulmonary bypass.

The results of the present study and others cited are consistent with respect to the haemodynamic and myocardial metabolic effects of propofol. In clinical practice it would seem prudent to treat the hyptension occurring at induction of anaesthesia with propofol.

Changes in plasma lipid concentrations (propofol is formulated in an egg-lecithin mixture), liver enzymes, or plasma cortisol levels were similar in both treatment groups during the $24 \mathrm{hr}$ after surgery, which is consistent with previous studies. ${ }^{21,23,24}$ The present study extends these observations to more prolonged and stressful surgery and demonstrates that propofol did not inhibit the stress response to any greater extent than enfluranesufentanil anaesthesia. Whether differences between the two groups would have occurred had our sampling for cortisol been more frequent is unknown.

We conclude that, apart from hypotension on induction, administration of propofol in combination with sufentanil for induction and maintenance of anaesthesia for cardiac surgery was not associated with increased haemodynamic instability, myocardial dysfunction, or with an ability to mount a stress response compared with sufentanil-enflurane anaesthesia. No difficulties were encountered with respect to liver function or the ability to handle lipids. Propofol did not lead to any increased incidence of death, major neurological injury, or myocardial infarction. However, in this study, propofol administration was not associated with earlier tracheal extubation or discharge from the intensive care unit. We believe this to be in part related to additional use of CNS depressants perioperatively. Our hypothesis that propofol would have no increased unwanted effects on myocardial oxygenation and metabolism compared with a standard cardiac anaesthetic technique appears to be correct.

\section{Acknowledgements}

The authors would like to acknowledge the assistance of the following for making the study possible: A. McIntyre MD FRCPC, J. Glenn MB ChB FRCPC, R. McLaren MB BS FRCPC, R. Barker MB ChB FRCPC, K. Fairhurst MB ChB FRCPC, D. Imrie MB BS FRCPC, J. Smith MD FRCPC, C. Allen MB BS FRCPC, D. Murphy MD FRCS, J. Sullivan MD FRCS, E. Kinley MD FRCS, J. Wood MD FRCS, the Nursing staff of $11 \mathrm{~B}$ OR and CVICU, and Miss Polly Moores for secretarial assistance.

\section{References}

1 Philbin DM, Rosow CE, Schneider RC et al. Fentanyl and sufentanil anesthesia revisited: how much is enough? Anesthesiology 1990; 73: 5- I1.

2 Hug CC Jr. Does opioid 'anesthesia' exist? Anesthesiology 1990; 73: 1-4.

3 Goldman L, Shah MV, Hebden MW. Memory of cardiac anesthesia. Anesthesia 1987; 42: 596-603.

4 Hilgenberg JC. Intraoperative awareness during high-dose fentanyl-oxygen anesthesia. Anesthesiology 1981; 54: 341-3.

5 Cross AS, Rorep B. Role of respiratory assistance devices in endemic nosocomial pneumonia. Am J Mcd 1981; 70: 681-5.

6 Dixon RE. Nosocomial respiratory infections. Infect Control $1983 ; 4: 376-81$

7 Corssen G, Reves JG, Stanley TH. Pharmacology of 
narcotic analgesics. In: Corssen G, Reves JG, Stanley TH (Eds) Intravenous Anesthesia and Analgesia, Philadelphia, Lea and Febiger, 1988; 39-60.

8 Hall RI, Moffit EA. The effects of ancsthetics on the coronary circulation: studies in animals and man. J Clin Anesthesiol 1989; 3: 27-46.

9 Sebel PS, Lowdon JD. Propofol: a new intravenous anesthetic. Anesthesiology 1989; 71: 260-77.

10 Patrick MR, Blair IJ, Feneck RO, Sebel PS. A comparison of the haemodynamic effects of propofol ('Diprivan') and thiopentone in patients with coronary artery disease. Postgrad Med J 1985; 61 (Suppl 3) 23-7.

11 Stephan H, Sonntag H, Schenk HD, Kettler D, Khambatta $H J$. Effects of propofol on cardiovascular dynamics, myocardial blood flow and myocardial metabolism in patients with coronary artery disease. $\mathrm{Br} \mathrm{J}$ Anaesth 1986; 58: 969-75.

12 Kaplan JA, Guffin AV, Mikula S, Dolman J, Profeta $J$. Comparative hemodynamic effects of propofol and thiamylal sodium during anesthetic induction for myocardial revascularisation. Journal of Cardiothoracic Anesthesia 1988; 3: 297-302.

13 Russel GN, Wright EL, Fox MA, Douglas EJ, Cockshott ID. The haemodynamics and pharmacokinetics of propofol in patients undergoing cardiopulmonary bypass procedures. Proceedings of the scientific session: The Haemodynamic Effects of Propofol: Mechanisms and Implications. 9th World Congress of Anesthesiologists, Washington, DC, May 1988.

14 White PF, Mora CT, Dudek C, Epstein R, Torjman $M$. Comparison of fentanyl, thiopentone, and propofol for maintenance of anaesthesia during cardiac surgery. Proceedings of the scientific session: The Haemodynamic Effects of Propofol: Mechanisms and implications. 9th World Congress of Anesthesiologists, Washington, DC, May 1988.

15 Vermeyen KM, Erpels FA, Janssen LA, Beeckman CP, Hanegreefs $G H$. Propofol-fentanyl anaesthesia for coronary bypass surgery in patients with good left ventricular function. Br J Anaesth 1987; 59: 1115-20.

16 Massey NJA, Sherry KM, Oldroyd S, Peacock JE. Pharmacokinetics of an infusion of propofol during cardiac surgery. Br J Anaesth 1990; 65: 475-9.

17 Merin RG. Propofol causes cardiovascular depression. I. Anesthesiology 1990; 72: 393-4.

18 VanAken $H, B r u s s e l T$. Propofol causes cardiovascular depression. II. Anesthesiology 1990; 72: 394-5.

19 Lippmann M, Mok MS. Propofol causes cardiovascular depression. III. Anesthesiology 1990; 72: 395.

20 Sebel PS, Lowdon JD. Propofol causes cardiovascular depression. Reply. Anesthesiology 1990; 72: 396.
21 Fragen RJ, Weiss $H W$, Molteni A. The effect of propofol on adrenocortical steroidogenesis: a comparative study with etomidate and thiopental. Anesthesiology 1987; 66: 839-42.

22 Flood J, Liedthe $R$, Mattenheimer $H$ et al. A multicentre evaluation of the Boehringer Mannheim/Hitachi 717 System. Clin Biochem 1990; 23: 477-88.

23 Stark RD, Binks $S M$, Dutka VN, O'Connor KM, Arnstein $M J A$, Glen JB. A review of the safety and tolerance of propofol ('Diprivan'). Postgrad Med J 1985; 61 (Suppl 3): 152-6.

24 Kay NH, Uppington J, Sear JW, Allen MC. Use of an emulsion of ICI 35868 (PROPOFOL) for the induction and maintenance of anaesthesia. $\mathrm{Br} \mathrm{J}$ Anaesth 1985; 57: $736-42$. 